\title{
As correntes de pensamento que influenciaram as ideias de Joaquim Francisco de Assis Brasil
}

The thought chains that had influenced the ideas of Joaquim Francisco de Assis Brasil

\author{
Vanderlei Beltrão de Vargas \\ Instituto Federal de Farroupilha - IF - São Vicente do Sul - Rio Grande do Sul - Brasil

\section{Olgário Paulo Vogt} \\ Universidade de Santa Cruz do Sul - UNISC - Santa Cruz do Sul - Rio Grande do Sul - Brasil
}

\begin{abstract}
Resumo: Joaquim Francisco de Assis Brasil foi um dos gaúchos de maior destaque no cenário político regional e nacional durante a República Velha. O presente artigo tem como objetivo mostrarum pouco de sua trajetória como político diplomata e escritor e relacionar suas ideias com as correntes políticas que influenciaram seu pensamento, a saber: positivismo, liberalismo e fisiocracia. Trata-se de uma pesquisa bibliográfica que procurou relacionar estas ideologias com as ideias de Assis Brasil em seus escritose pronunciamentos. Concluiu-se, através do presente estudo, que o positivismo teve pouca influência sobre as ideias de Assis Brasil, notadamente nos seus primeiros anos de estudo, mas que o liberalismo e a fisiocracia acompanharam este personagem histórico durante toda a sua trajetória, como se pode ver na comparação entre suas ideias e as das ideologias apresentadas.
\end{abstract}

Palavras-chave: Joaquim Francisco de Assis Brasil. Correntes de Pensamento. Influências.

\begin{abstract}
Joaquim Francisco de AssisBrasil was one of the most prominent Gauchos in regional and national political scene during the old Republic. This article aims to show a bit of his career as a politician, diplomat and writer and relate their ideas with political currents that have influenced his thinking, namely: positivism, liberalism and physiocracy. It is a bibliographical research that sought to relate these ideologies with the ideas of AssisBrasil in his writings and pronouncements. It was found, by means of this study, which the positivism had little influence on the ideas of AssisBrasil, notably in their first years of study, but liberalism and physiocracy accompanied this historic character throughout its trajectory, as can be seen in the comparison between his ideas and those of the ideologies presented.
\end{abstract}

Keywords: Joaquim Francisco de AssisBrasil. Chains of Thought. Influences. 


\section{Introdução}

A natureza histórica do homem é construída pelas influências de sua época, contribuindo, assim,na mudança da situação em que vive, com significativas alterações no modo de ser e pensar de sua comunidade.

Para Assis Brasil, "os homens são grandes ou pequenos, heróis ou imbecis, segundo a natureza do meio que os cerca. Os homens são filhos das circunstâncias" (Arquivo Assis Brasil/ Câmara dos Deputados, 1983).

Para melhor compreensão do que será abordado, começamos do século XIX e início do século XX,mais precisamente no Estado do Rio Grande do Sul, situado no extremo meridional do Brasil onde se estabeleceu uma região diferenciada. Faz fronteira com os países do Prata, fronteira essa, imersa em guerras contínuas, tanto internas como externas.Neste período, apresentavam-se grandes extensões de terra, como na Serra e na parte Norte, e ainda não totalmente povoadas, que estavam sendo ocupadas paulatinamente por imigrantes. Além disso, uma incipiente classe média urbana começava a surgir nos pequenos centros urbanos.

A região da campanha possuía uma ocupação mais antiga, o foi gado trazido pelos jesuítas para as Missões e, após a guerra guaranítica, disseminou-se pelas pradarias onde cresceu e multiplicou-se pela ausência de inimigos naturais, consequentemente tornou-se sua principal atividade econômica com a produção do charque. A ocupação da campanha gaúcha se deu em função desta oportunidade de aproveitar sua carne para consumo e venda ao resto do País. A charqueada se virou o símbolo da produção gaúcha e gerou uma classe de estancieiros que dominava a economia e a política da época (TARGA, 1996).

Era costume, na época, que os filhos dos estancieiros fossem estudar na Europa ou nos centros acadêmicos do Brasil, como a Faculdade de Direito de Recife ou a Faculdade de Direito de São Paulo. Nestas instituições, tomavam contato com as ideias proeminentes da época e, após a sua formação, geralmente voltavam para o Estado e passavam a comandar a política local (WEISS, 2010).

Dentre estes personagens que influenciaram na época está Joaquim Francisco de Assis Brasil, intelectual liberal que exerceu cargos importantes na diplomacia brasileira e ainda participou de momentos decisivos da história rio-grandense. Por ser um grande escritor, escreveu inúmeros livros sobre política e desenvolvimento rural, tendo sido pioneiro na experimentação de novas formas de cultivo e criação de animais. Neste artigo, apresenta-se uma pequena biografia e as ideias que influenciaram seu pensamento.

\section{Quem foi Joaquim Francisco de Assis Brasil}

No ano de 1857, em 29 de julho, na Estância São Gonçalo, localizado em Cacequi (RS), à época município de São Gabriel (RS), nascia Joaquim Francisco de Assis Brasil.

Segundo historiadores Joaquim Francisco de Assis Brasil entrou na escola do mestre Custódio José de Miranda, aos oito anos de idade. Em 1870 transferiuse para o Colégio São Gabriel. Em 1872, já órfão de pai, partiu para Pelotas, ficando interno no Colégio Taveira Júnior. Em 1874, cursou em Porto Alegre, o Colégio Gomes, onde estudou os preparatórios.

Quando adulto, ingressou na Faculdade de Direito de Recife e, posteriormente, transferiu-se para a Faculdade de Direito de São Paulo. Foi no contato com os colegas que desabrochou para a política, pois a referida instituição era um centro de efervescência cultural no período de transição do governo monárquico para a República. O jovem acadêmico sentiu que estava na hora de participar daquele momento histórico para o País e para sua terra natal. (WEISS, 2010, p. 103).

Após a sua formatura, volta ao Rio Grande e encontra umaprovíncia em ebulição. Juntamente com Júlio de Castilhos, ajuda a fundar o Partido Republicano RioGrandense (PRR), que comandaria a província durante toda a República Velha, sendo eleito, em 1884, como Deputado Provincial. 
Em 1891, rompe sua aliança política com Júlio de Castilhos, por não concordar com a criação e promulgação da Constituição Estadual, que foi escrita pelo primeiro e constituía uma versão local do positivismo, corrente de pensamento que influenciou toda uma geração de políticos gaúchos. Assis Brasil passa a integrar, então, a oposição, fazendo parte de diferentes partidos durante toda a República Velha, com o intuito de fazer disseminar suas ideias de cunho liberal(ROCHA, ALMEIDA E MARCHIORI, 1995).

Durante sua vida, duas outras atividades merecem destaque em sua trajetória. A primeira delas é a carreira de diplomata, através da qual exerceu diversos cargos de representação do Brasil pelo mundo, dando importante contribuição ao País na solução de conflitos entre países ou na melhoria de relações com o Estado Brasileiro. A segunda delas foi a sua atividade como promotor do desenvolvimento rural, trazendo para a sua granja, em Pedras Altas, novas espécies de cultivo e novas raças de animais para incrementar a atividade econômica da época (ROCHA, ALMEIDA E MARCHIORI, 1995).

Durante a carreira política, foi deputado provincial e nacional, diplomata, candidato a governador, chefe político da oposição rio-grandense e ministro da agricultura. Participou da elaboração de constituições estaduais e nacionais e foi o idealizador do Código Eleitoral de 1932, tendo ainda publicado uma obra que serviu de base para a Constituição de 1934.

Além disso, era um homem de imensa cultura e conhecimento, tendo viajado pelo mundo a procura de novas ideias e experimentos. Em sua biblioteca estava presente a maior parte dos clássicos da época, cuja leitura influenciou suas ideias e sua prática.

\section{0 positivismo}

A história do RS não pode ser contada sem alusão ao positivismo, que aqui encontrou grandes adeptos que o utilizaram como matriz teórica, adaptando-a ao seu estilo, permanecendo como uma ideologia viva e presente em diversos campos do saber. Entre os membros do Partido Republicano RioGrandense (PRR), era a forma de pensamento que norteava suas ações e Assis Brasil compartilhava de algumas de suas ideias até seu rompimento com Julio de Castilhos.

O positivismo, teoria elaborada por Augusto Comte, propunha uma reforma intelectual do ser humano em direção a um estado positivo, onde a obtenção de novos hábitos teria a capacidade de pensar a sociedade em conformidade com as ciências de seu tempo (PEREIRA, 2006, p. 97).

Verifica-se no trecho abaixo:

Este sistema levaria a paz à sociedade e a estabilidade ao regime político. $O$ desenvolvimento científico e industrial levaria ao progresso e à felicidade humana. (...) É uma doutrina geral que, simultaneamente, pretendeu satisfazer a razão, o sentimento e a imaginação, coordenando os diferentes aspectos da existência humana: pessoal, social, especulativa, ativa e afetiva (PEREIRA, 2006, p. 98).

Apregoa Comte que o homem, como um ser social, propunha que se estudasse a sociedade cientificamente, de forma análoga às ciências da natureza, sugerindo a ideia de uma física social (a sociologia), que seria criada para estudar os fatos humanos. E, assim como nas ciências exatas, descobrir as suas leis de funcionamento, usando os procedimentos, métodos e técnicas já empregadas nas ciências da natureza. (CHAUÍ, 1995, p. 272).

Nesse sentido:

A sociedade, para Comte, era governada por leis imutáveis e independentes da vontade do indivíduo ou do coletivo. Era da mesma natureza das que governavam a física ou a biologia, mas com especificidades próprias e peculiares à sociedade e aos fenômenos sociais. (...) Esta dependia da ordem e da harmonia para progredir, assim como de instituições fortes e permanentes. A sua transformação, evolução ou desenvolvimento dependia da transformação e do desenvolvimento do espírito humano, que seria o desenvolvimento das ideias e da moral (PEREIRA, 2006, p. 101).

O positivismo chegou ao Rio Grande do Sul pelas mãos dos estudantes de direito da Faculdade de São Paulo. Conforme o interesse dos novos 
dirigentes foi modificado, chegando a ser chamado de "Castilhismo", em referência a Julio de Castilhos, que instrumentalizou as ideias de Comte em proveito do seu grupo político.

Para Ricardo Vélez Rodrigues:

O castilhismo partia do princípio de que a sociedade caminha inexoravelmente rumo à sua estruturação racional. Atingem-se esta convicção e os meios necessários para tornála realidade através do cultivo da ciência social. Esta é, sobretudo, privilégio de personalidades carismáticas, que se impõem nos meios sociais nas quais se encontram. Quando uma personalidade esclarecida pela ciência social assume o governo, pode transformar o caráter de uma sociedade que levou séculos para constituir-se (RODRIGUEZ, 2005, P. 37).

Ordem e progresso, que são os mesmos dizeres presentes na bandeira brasileira, oferecendo um exemplo claro de sua influência, eram a condição sinequa non para o desenvolvimento da sociedade dentro dos paradigmas do positivismo. Ordem, através de uma sábia resignação, para que a sociedade estivesse bem estruturada, com instituições fortes e valores permanentes: e progresso para a evolução constante do pensamento e da organização social, através do conhecimento científico (MOURA, 2014).

Das ideias de Comte resultou a crença em um governo republicano e ditatorial a serviço da ordem social e do progresso constante (TRINDADE e NOLL, 2005, p. 16).O positivismo forneceu o ideário perfeito para que um pequeno grupo se encastelasse no poder durante a República Velha.

Assinala Pesavento (1992, p. 38):

No tocante ao poder, a "monocracia" de Comte pressupunha que o grupo no poder, que detinha o conhecimento teórico, era o mais habilitado para condicionar o progresso econômico. Na prática, este grupo desdobrava-se em dois: a elite dos sábios e os empresários industriais, aos quais ficariam afetas as tarefas de garantir a ordem e assegurar o progresso, cada qual na sua instância. $\mathrm{O}$ autoritarismo do mando, presente na concepção positivista, atenuava-se, contudo, em razão da legitimação do governo dos mais aptos, que só ocupariam aquela função tem em vista o bem comum.
Apesar da maioria dos gaúchos e dos integrantes do PRR nunca terem tido contato com a obra de Comte, a tônica dos discursos da época mostrava a influência do positivismo na determinação da condução política do Estado.

Anota TRINDADE e NOLL:

Esta assimilação do positivismo através de um longo período transforma-se não somente na cultura política dominante no Rio Grande do Sul, mas a experiência política e institucional da ditadura republicana Castilhoborgista será fundamental para entender o contexto em que se formam, politicamente, Getúlio Vargas e outros membros de sua geração em suas carreiras políticas locais e nacionais antes da década de 30. Essa geração formada no recinto da Assembleia dos Representantes recebeu uma influência direta do ideário positivista e foi marcada, também, pelo contingenciamento do espaço reservado aos deputados dentro da Câmara Orçamentária (TRINDADE; NOLL, 2005, p. 23).

Julio de Castilhos e, posteriormente, seu sucessor, Borges de Medeiros tiveram a oportunidade de implantar um governo de cunho positivista no Estado, através de uma ditadura republicana que conduzia o Estado no sentido de corrigir os privilégios individuais em favor da solidariedade, da igualdade social e do estímulo à produção (PEREIRA, 2006, p. 97).

No plano econômico, havia uma intervenção estatal considerada essencial para desenvolver 0 Estado, o que nem sempre agradava a elite da época, os estancieiros. Por este motivo:

(...) seu plano econômico para o Estado rompia com os preceitos de uma economia agroexportadora, cuja produção é pautada pela demanda externa. Ao contrário, exportar significava apenas vender ao exterior o que a economia interna não absorveu: exporta-se o excesso, depois de abastecido o mercado local, que deve produzir tanto quanto for possível para satisfazer suas necessidades. (...) As exportações eram assim consideradas como mercados para o excedente da produção estadual e não como forma adequada para manter o nível de renda estadual (HERRIÉN JÚNIOR, 2000, p. 63). 
Coerente com a sua doutrina, Julio de Castilhos, criou, com a Constituição de 1891, um governo centrado no Executivo, cabendo ao legislativo e ao judiciário um papel secundário, o de acatar suas deliberações.

Ao mesmo tempo a assembléia legislativa era puramente orçamentária e a votação das matérias nela discutidas deveria ser efetivada mediante 0 mecanismo do voto a descoberto. A sua missão não consistia em legislar, mas em votar o projeto de gastos que 0 Executivo Ihe apresentava. E 0 Judiciário ficava em mãos do Executivo, ao serem os seus membros nomeados pelo Presidente do Estado, segundo dispunha a Constituição Gaúcha de 14 de julho de 1891 (artigos 7 a 11, 21 e 31 a 33), de autoria de Júlio de Castilhos (RODRIGUEZ, 2005, p. 37-38)

Assim se posicionando, Assis Brasil busca uma eficácia simbólica para seu texto que extrapola o mundo das opiniões político-partidárias, das então comummente chamadas "doutrinas", pois o situa no campo da "ciência" e da "verdade natural" (Assis Brasil, 1882, p. 581).

O positivismo influenciou Assis Brasil nos primeiros momentos de sua atuação política. Em seus primeiros escritos, como o livro história da República Rio-Grandense, ou ditadura, democracia e parlamentarismo, demonstrava suas ideias de ordem e progresso, evolução e leis científicas. Demonstra o trecho abaixo esta influência, quando garante que em uma sociedade poucos governam muitos, como afirma o projeto de ditadura comteana:

A realidade sobre a direção social é que cada povo é governado,ou dirigido, por uma minoria inteligente. O que importasaber é se essa minoria se institui por si mesma, por algummeio ilusório de nomeação popular, ou por legítima representaçãodo povo. Importa ainda saber como opera essa minoriadiretora, se enfeixando os poderes em uma só autoridade,ou dividindo as funções de modo a evitar 0 desequilíbrio pelocrescimento exagerado de um órgão com o aniquilamento deoutros (BRASIL, 1908, p. 30).

No tópico a seguir, analisa-se a influência do liberalismo sobre as ideias de Assis Brasil.

\section{Liberalimo}

O liberalismo como corrente do pensamento, orientou a conduta política de J.F. Assis Brasil e tornou-se vital para compreensão de seu modo de agir e pensar. Surgido no Antigo Regime como uma ideologia criada pela classe em ascensão, a burguesia, como ferramenta ideológica para lutar contra os abusos da autoridade real e os privilégios do clero e da nobreza, que inibiam a produção, a circulação, o comércio e o trabalho livre (AITA, 2006, p. 31).

Um dos pressupostos chaves do liberalismo é a propriedade privada, única capaz de garantir a plena liberdade de mercado e uma economia saudável, do qual restarão sobreviventes aqueles que se mostrarem mais aptos a apresentar um produto melhor, mais barato e capaz de satisfazer o mercado. A propriedade privada reafirma o caráter individual e livre do homem, tão livre que nem a sociedade e nem o governo podem sobrepô-la (MALFATTI, 1985, p. 93).

Para os teóricos do liberalismo, deve haver liberdade total em termos econômicos e políticos. Economicamente falando,deve haver a liberdade de iniciativa, entendida como o direito de entrada no mercado para produzir os bens e serviços que os consumidores desejam. É uma liberdade de contrato no qual as partes estabelecem preços, salários e juros sem restrições de qualquer natureza, constituindo-se a atividade produtiva em um risco de alguém somete ser bem-sucedido se produzir algo melhor e mais barato. Politicamente falando, deve haver a liberdade de expressão, de locomoção, de crença, de reunião, sendo a consciência de cada um que move o agir, que orienta a escolha de representantes e que promove o debate de ideias de forma livre, sem cerceamentos (STEWART JR., 1990, p. 74).

Incrementa Stewart Jr.:

O liberalismo não pode ser imposto à força ou pela proibição de partidos políticos; tem que se impor pela persuasão e pelo argumento, pela explicação de suas vantagens como um todo e para cada um em particular. As 
tentativas de impor a liberdade econômica sem a correspondente liberdade política são uma contradição. Mesmo um eventual e episódico sucesso econômico não pode servir para supressão da liberdade política. Se houver liberdade política, podemos lutar pela liberdade econômica; se não houver, temos que nos conformar com as determinações do caudilho, general ou ditador a que estivermos submetidos (STEWART JR., 1990, p. 74).

Decorrem do ideário liberal: a garantia dos direitos individuais, como a liberdade de pensamento, a liberdade religiosa, o que supõe um estado de direito; um sistema de representação e de autonomia e divisão dos poderes; a economia de mercado baseada na livre iniciativa, na competição e na propriedade privada, sem a intervenção do Estado. É uma teoria que consagra um modelo de autorregulação social e econômica, sem a intervenção do Estado, em que produtores e consumidores, através da livre concorrência e seguindo a lei da oferta e da procura, irão ajustando o mercado de bens e serviços para uma situação considerada ideal, na qual haverá o preço justo para cada mercadoria.

Nesse desdobramento:

Dentre as ideias de mais comum e diária aplicação, a propósito de qualquer incidenteda vida individual, ou social, nenhuma se repete mais que a ideia de liberdade. Apesardisso, é raro que o critério popular a empregue com precisão e propriedade. O público,em geral, e cada um de nós, que o compomos, confundimos vulgarmente liberdadecom comodidade. Indivíduo que sofra qualquer incômoda exigência do poderconstituído grita logo que atentam contra a sua liberdade, e não se queixa de que ela nãoexista, enquanto o deixam em casa sossegado. Povo que atravesse quadra tranquila epróspera reputase gozando de um regime de liberdade, e considera-se presa de tirania oque se debate em agitações internas.Liberdade não é, porém, comodidade, e pode existir sem ela, bem que seja preferívelpossuí-las ambas conjuntamente. O bom senso do fabulista Lafontaine, repetindo outromoralista mais remoto, mostrou na situação do cão doméstico, forte e satisfeito,comparada à do lobo selvagem, faminto e vagabundo, que esta distinção, emboraestranha ao comum dos espíritos, é bem antiga. O cão de guarda, marcado pelo estigmada coleira, que the pelara o toutiço, não era livre, apesar de viver muito ao seu cômodo.Era-o, entretanto, o animal silvestre, bem que torturado pelas mil necessidades a quetinha de dar provimento com o seu exclusivo esforço (BRASIL.1988, p. 25).

Sintetizando o que foi exposto, Montaner (2013, p. 1), fundamenta o liberalismo em quatro premissas básicas, sejam elas: a) o exercício da liberdade individual é uma condição insubstituível para alcançar níveis ótimos de progresso, através da liberdade de possuir bens, condição que deve ser garantida pelo Estado que está a serviço do cidadão; b) assim sendo, as pessoas são responsáveis por seus atos, devendo considerar quais serão a consequência de seus atos e os direitos dos demais indivíduos; c) para garantir os direitos e deveres em relação aos outros, há necessidade de criar um Estado de direito, cujas leis sejam neutras e não favoreçam as pessoas, partidos e grupos, evitandose, desta forma, os privilégios; d) assim, a sociedade deve controlar rigorosamente as atividades dos governos e das instituições de Estado. Há um compromisso do cidadão e da sociedade com a organização e o funcionamento do poder político.

Essa ideia está clara no seguinte fragmento de discurso:

Sem representação não há Estado livre. Ela é da própria essência de todo governoconstitucional. Já observei que até os nossos ditatoriais, embora anatematizem no seusyllabus a autoridade do povo, não dispensaram o sufrágio popular para umas tantascousas, inclusive para escolher os seus únicos capazes que devem de cinco em cincoanos ser chamados à magistratura suprema do Estado. Como em outros casos, pois doque se trata não é do mérito da cousa em si, mas do modo de a pôr em operação.Os artifícios eleitorais que temos ensaiado até agora no Brasil são todos viciosos; algunso são total e grosseiramente, outros apenas em certa extensão (BRASIL, 1908, p. 114-115).

Assis Brasil, como um dos adeptos das ideias liberais, criticava a demasiada concentração de poderes no executivo, razão pelo qual chamava o regime implantado pelo PRR de despótico. Para ele, no Rio Grande do Sul, não havia regime constitucional, pois o poder executivo exercia também as funções do legislativo e ainda dominava o judiciário. Isto ia contra a divisão de poderes postulada por Montesquieu. 
Veja-se:

A situação é mais grave, ainda, diz Assis Brasil, quando se tem em conta que os representantes à Assembleia do Estado não gozam do poder de legislar, mas têm simplesmente funções orçamentárias. (...)O Presidente, continua o liberal gaúcho, exerce também de direito e de fato o Poder Judiciário. Enquanto na maioria das nações livres o Ministério Público é indicado pelas autoridades judiciais superiores, (...) no Rio Grande do Sul o artigo 60 da Constituição atribui ao Presidente a nomeação dos membros do Ministério Público. Assim, se os promotores querem conservar-se nos cargos devem converter-se em instrumentos do despotismo legal imperante (ASSIS BRASIL apud RODRIGUEZ, 2000, p. 196).

Além destas críticas, Assis Brasil também condenava o sistema eleitoral, criado para votar sempre os membros da elite, diferente do que propunha o ideário liberal. Assim, em vez de eleger representantes para defender seus interesses, 0 eleitor estaria atrelado a uma máquina eleitoral que conduziria, sempre, ao poder, a mesma minoria. Então, Assis Brasil deixava claro duas coisas: a representação do povo e o controle do poder por parte do mesmo, a fim de evitar o despotismo.

No livro A democracia representativa na República:

O remédio que o povo tem contra os possíveis desvios dos seusrepresentantes não pode ser o mandato imperativo, que, além de serantijurídico, acanharia a inteligência e a ação destes e Ihes ofenderia ocaráter, pela sujeição a movimentos materialmente determinados. Esseremédio é a temporariedade. Permanência da função e renovação dosfuncionários é uma das mais fecundas fórmulas democráticas (BRASIL,1998, p. 140).

A liberdade constituía, para Assis Brasil, uma exigência também no plano econômico, conforme pontua Rodrigues (2000, p. 189). Segundo Assis Brasil, a educação e a riqueza de um povo estão em relação proporcional com a sua liberdade. "Dá-me um povo educado e rico e eu respondo pela sua liberdade, pela sua felicidade". Assim é que é que se pode combater o perigo da tirania nas sociedades democráticas.

Verifica-se nas palavras de Assis Brasil:
Um governo que promove a educação e a riqueza dapopulação estará poupando os gastos relativos à força pública para exercer a tutela oficial, porque a sociedade saberá para onde marcha. Dispensará, também, o protecionismo exagerado para as indústrias, pois o povo terá iniciativa na criação da riqueza (ASSIS BRASIL apud RODRIGUES, 2000, p. 189).

Assis Brasil entendia que um sistema opressivo como o castilhista não poderia manter-se no seio de qualquer dos povos ricos e educados da época, pois a educação é condição necessária para o funcionamento de um governo representativo, no qual os cidadãos possam participar das eleições e da atividade legislativa, pois somente povos ignorantes deixam que outros elejam e legislem por eles.

\section{Fisiocracia}

Outra corrente de pensamento que influenciou as ideias de Assis Brasil foram os fisiocratas, considerados por Marx (1978, p. 36) como os primeiros economistas da sociedade moderna. Estes pensadores visualizavam as formas de produção como fisiológicas e essenciais à sociedade, impostas pela necessidade natural de produção, entendendo que esta estava associada às leis materiais de uma determinada sociedade.

A própria palavra fisiocracia pode ser traduzida como governo da natureza.

Existe uma ordem natural e essencial à qual estão sujeitas as convenções sociais, e é esta ordem que assegura aos homens reunidos em sociedade o gozo de todos os seus direitos, mediante a observância de todos os seus deveres. A submissão exata e geral a esta ordem é a condição única que permite todos esperar e merecer a participação em todas as vantagens que a sociedade pode proporcionar a si mesma (CARDOSO, 1966, p. 50).

Os fisiocratas entendiam que três classes distintas estavam ligadas ao sistema econômico: a produtiva, a proprietária e a estéril.

Segue:

A classe produtiva é a que faz renascer, pelo cultivo do território, as riquezas anuais da nação, efetua os adiantamentos das despesas com os trabalhos da agricultura e paga 
anualmente as rendas dos proprietários das terras. [...] A classe dos proprietários compreende o soberano, os possuidores de terra e os dizimeiros. Essa classe subsiste pela renda ou produto líquido do cultivo da terra, que lhe é pago anualmente pela classe produtiva, depois que esta descontou, da produção que faz renascer cada ano, as riquezas necessárias ao reembolso de seus adiantamentos anuais e à manutenção de suas riquezas de exploração. [...] A classe estéril é formada por todos os cidadãos ocupados em outros serviços e trabalhos que não a agricultura, e cujas despesas são pagas pela classe produtiva e pela classe dos proprietários, os quais, por sua vez, tiram suas rendas das classes produtivas (QUESNAY, 1996 - E, p. 43).

Deste modo, a atividade rural seria a única verdadeiramente produtiva porque só ele poderia gerar um excedente, só ela poderia produzir mais do que gastava para isso, pois os trabalhos da agricultura compensavam os gastos, pagavam a mãode-obra da cultura, proporcionavam ganhos aos lavradores e, além disso, produziam os rendimentos dos bens territoriais. Ou seja, o comércio e a manufatura só sobreviveriam porque existia a atividade rural que Ihes fornecia a matéria-prima com que trabalhavam. "Com efeito, sem os produtos de nossas terras, sem os rendimentos e despesas dos proprietários e dos cultivadores, donde surgiriam 0 lucro do comércio e o salário da mão de obra", cita Kunts (1982, p. 22).

Segundo o pensamento fisiocrata:

Só pode haver um setor não-agrícola se houver um excedente agrícola, isto é, se os agricultores produzirem mais que 0 necessário à sua vida e à manutenção de sua atividade. Assim, quanto maior a atividade rural, ou seja, quanto maior o produto por trabalhador empregado no campo, tanto mais poderá desenvolver-se a economia urbana (KUNTZ, 1982, p. 22).

Deste pensamento é que entende-se terem saído as premissas para que Assis Brasil desenvolvesse as ideias a respeito do desenvolvimento econômico com base na agricultura.

Da terra nos vem tudo e cuidar da terra como deve ser cuidada é o primeiro dever não só do homem, senão e principalmente dos administradores, desses que têm nas mãos as rédeas do governo, Quando mais um administrador, um governo, se preocupa em fazer produzir a terra, de dar o bem-estar ao homem, ao lavrador, de admirá-lo mesmo, de respeitá-lo, porque é mais digno de respeito do que ninguém, mais, tanto mais, esse administrador, político ou governo, merece os meus aplausos (CORREIO DO POVO, 1911).

Os fisiocratas inverteram a lógica que considerava a agricultura como um símbolo da miséria e do atraso, conferindo a esta uma importância ímpar, como fornecedora de insumos indispensáveis para a vida em sociedade e para o fomento da economia.

Nada há melhor que a agricultura, nada há mais produtivo, mais agradável, nem mais digno do homem livre - "Nihil est agricultura, nihiluberius, nihildulcis, nihilhominedignus". Estas palavras, verdadeiras já no tempo de Cícero, que as proferiu há dezoito séculos, deviam ser gravadas no coração da mocidade atual, como um dos meios mais energéticos da regeneração da Pátria (BRASIL, 1908, p. XIV).

Outra questão importante a ser analisada na teoria fisiocrata era o papel da educação na produção e transformação da economia. De acordo com Ricardo (2009, p. 26), as mudanças econômicas de um país seriam resultantes das transformações na política e nos métodos de educar os cidadãos, pois a população agrícola produziria mais se houvesse uma instrução mais direcionada ao ofício a que se empregava. Dessa forma defendiam a instrução pública como uma medida necessária para garantir que 0 conhecimento se expandisse entre os agricultores. Teve importante evidência neste tema Dupont de Neumors, que defendia uma educação simples, mas ao mesmo tempo moral e filosófica, ensinando à juventude as técnicas da agricultura e do artesanato.

Foi a partir destas premissas educacionais dos fisiocratas que Assis Brasil preconizou a necessidade de investir na formação das pessoas. De acordo com Rocha, Almeida e Marchiori(1995, p. 39), ele considerava o binômio Educação - Riqueza passível de incrementar a prosperidade para o indivíduo e para a nação, através do trabalho "persistente, contínuo, corajoso para vencer os tropeços do caminho, confiante no resultado final." Afinal, se a 
terra é um lugar em que o homem trabalha e se, para o êxito desse trabalho ele precisa de educação, "a educação, neste caso, não é juntar letras e palavras e períodos, escrever livros e fazer discursos: é aptidão para jazer produzir." De acordo com os autores, Assis Brasil falava sobre a necessidade de se dedicar a ela a maior cota possível das receitas do tesouro nacional, sobre o quanto era inadiável o problema educacional - uma verdadeira "questão de vida ou morte", afirmando não entender "como possa ser livre um povo ignorante e pobre, nem como possa deixar de ser escravo um povo pobre e ignorante." (ROCHA, ALMEIDA e MARCHIORI, 1995, p. 39).

\section{Conclusão}

Associa-se a figura de Joaquim Francisco de Assis Brasil (1857-1938) à propaganda republicana no Segundo Reinado, às lutas políticas do Rio Grande do Sul na Primeira República, ao seu porfiado combate pela democracia representativa, à sua reflexão sobre temas políticos, à preocupação com o progresso agrícola - sempre presente em todos os momentos de sua vida, no Brasil ou no exterior. (Assis Brasil. 2006, p. 07).

A principal luta formativa do liberalismo foi a reivindicação de direitos, quer religiosos, políticos ou econômicos, e de outra parte, a tentativa de controlar o poder político

Dessa monta:

Os princípios liberais no Brasil não se forjaram, no Brasil, na luta da burguesia contra os privilégios da aristocracia e da realeza. (...). Não existia no Brasil da época uma burguesia dinâmica e ativa que pudesse servir de suporte a essas ideias. Os adeptos das ideias liberais pertenciam às categorias rurais e sua clientela. As camadas senhoriais empenhadas em conquistar e garantir a liberdade de comércio e a autonomia administrativa e judiciária não estavam, no entanto, dispostas a renunciar ao latifúndio ou à propriedade escrava. A escravidão constituiria o limite do liberalismo no Brasil. (COSTA. 1999, p. 30).

O conjunto de ideias que forjou o caráter de Joaquim Francisco de Assis Brasil está centrada, principalmente, no liberalismo e na fisiocracia, apesar de ter sofrido uma pequena influência do positivismo em suas primeiras manifestações, fruto dos estudos na Faculdade de Direito de São Paulo.

Do liberalismo adquiriu a ideia de liberdade de ação para os indivíduos escolherem seu papel na sociedade, contribuindo para o desenvolvimento. Desta forma de pensamento incorporou a ideia de república, democracia e voto como os alicerces de um governo representativo, pautado pela divisão de poderes.

Da fisiocracia, incorporou o valor pela terra como a riqueza maior que produz outras riqueza e a educação como ferramenta para o desenvolvimento social e econômico.

Para os fisiocratas, toda riqueza provém da terra, a indústria apenas diversifica o fruto e o comércio dissemina. Eram contra o intervencionismo mercantilista. As ideias fisiocratas surgem na época que não existia atividade industrial, ou seja, apenas atividades ligadas ao setor primário, à agricultura, pois eles se mostravam contra a da nobreza na economia, sustentando assim 0 individualismo econômico.

\section{Referências}

AITA, Carmen S. A. Liberalismo \& república: o pensamento político de J. F. de Assis Brasil. Tese (Doutorado em História Íbero-Americana). Pontifícia Universidade Católica do Rio Grande do Sul, Porto Alegre, 1996.

ASSIS BRASIL. O opportunismo e a revolução, São Paulo: Typographia A. L. Garraux \&\& Comp. 1883. Arquivo Assis Brasil/ Câmara dos Deputados.

J.F. de. 1882. História da República RioGrandense. In: Paulo BROSSARD (org.), Ideias políticas de Assis Brasil. Brasília/Rio de Janeiro, Senado Federal/Casa de Rui Barbosa,vol. 3.

Um diplomata da república. chdd / funag. Rio de Janeiro, 2006.

BRASIL, J. F. de A. Ditadura, parlamentarismo, democracia. PortoAlegre: Globo, 1908. p. 30.

Cultura dos campos. Lisboa: [s.n.] 1898. Ideia de pátria. Conferência Pública realizada noTeatro Municipal de São Paulo, a 22 de setembro de 1917, sobre a 1aㅡ Tese dasérie organizada pela Liga da Defesa Nacional. São Paulo: Tipografia Piratininga,1918. 
A democracia representativa na $\overline{R e p u ́ b l i c a}$. Brasil: Senado Federal, 1988.

CARDOSO, T. Nota preliminar. In: QUESNAY, F. Quadro econômico. 3 ed.Lisboa: CalousteGulbenkian, 1966.

COSTA. Emília Viottida. Da monarquia à república. São Paulo: Fundação Editora da UNESP, 1999

HERRIEIN, Ronaldo J. Rio Grande do Sul, 18891930: Umoutro capitalismo no Brasil Meridional! Tese (Doutorado). Unicamp, Campinas, 2000.

MALFATTI, Selvino Antonio. Raízes do liberalismo brasileiro. Porto Alegre: Pallotti, 1995.

PEREIRA, Ledir de Paula. $O$ positivismo e o liberalismo como base doutrinária das facções políticas gaúchas na Revolução Federalista de 1893189e e entre Maragatos e Chimangos de 1923. Dissertação (Mestrado em Ciência Política). Universidade Federal do Rio Grande do Sul, Porto Alegre, 2006.

CHAUI, Marilena. Convite à filosofia. 4 ed. São Paulo: Ática, 1995.

KUNTZ, Rolf (Org.). François Quesnay: economia. Tradução de M. de C. Neves et al. São Paulo: Ática, 1984.

MOURA, José Adersino Alves de. O método positivista nas ciências sociais: o viés na história da educação. Disponível em: <http://www.ufpi.br/subsiteFiles/ppged/arquivos/files/e ventos/evento2004/GT.11/GT29.PDF>. Acesso em 29 mar.2014.

QUESNAY, François. Tableau Économique des Physiocrates. In: PETTY, William, QUESNAY, François. Os Economistas. Tradução de João Guilherme Vargas Netto; Apresentação de Roberto Campos. São Paulo: Nova cultural, 1996.

ROCHA, ArthenizaWeimann; ALMEIDA, Luiz Gonzaga Binato de; MARCHIORI, José Newton Cardoso. J. F. de Assis Brasil: interpretações. Santa Maria: Ed. UFSM, 1995.

RODRIGUES, Ricardo Vélez. Castilhismo: uma filosofia da república. Brasília: Senado Federal, 2002. (Coleção Brasil 500 anos).

STEWART JR., Donald. O que é liberalismo?. 4. ed. Rio de Janeiro: Instituto Liberal, 1990.

TARGA, Luiz Roberto Pecoits. O Rio Grande do Sul: fronteira entre duas formações históricas. In:

Gaúchos e paulistas: dez escritos de história regional comparada. Porto Alegre: FEE, 1986. p. 17-48.

TRINDADE, Helgio; NOLL, Maria Izabel. Subsídios para a história do parlamento gaúcho (1890-1937). Porto Alegre: CORAG, 2005.
PESAVENTO, Sandra Jatahy. A Assembleia Legislativa do Rio Grande do Sul: a trajetória do parlamento gaúcho. Porto Alegre: Assembleia Legislativa do Rio Grande do Sul, 1992.

WEISS, Jussemar. Trabalho, alimentação e natureza: a noção de gaúcho na obra História da República RioGrandense, de Assis Brasil. Biblos, Rio Grande, v. 1, n. 1, p. 103-113, 2010. 